Journal of Telenursing (JOTING)

Volume 1, Nomor 2, Desember 2019

e-ISSN: 2684-8988

p-ISSN: 2684-8996

DOI: https://doi.org/10.31539/joting.v1i2.853

\title{
PENDIDIKAN KESEHATAN MENGGUNAKAN MEDIA BOOKLET + APLIKASI SDIDTK EFEKTIF MENINGKATKAN KEMANDIRIAN KELUARGA DALAM PEMANTAUAN TUMBUH KEMBANG BALITA
}

\author{
Marwasariaty ${ }^{1}$ Titin Sutini ${ }^{2}$, Suhendar Sulaeman ${ }^{3}$ \\ Universitas Muhammadiyah Jakarta ${ }^{1,2,3}$ \\ Marwasariaty@yahoo.com ${ }^{1}$
}

\begin{abstract}
ABSTRAK
Penelitian ini bertujuan untuk mengidentifikasi pengaruh pendidikan kesehatan menggunakan media booklet dan media aplikasi SDIDTK terhadap kemandirian keluarga dalam pemantauan tumbuh kembang balita di wilayah kerja Puskesmas Bajo Barat. Penelitian ini menggunakan quasi eksperimental dengan pendekatan pre and post-test without control. Hasil penelitian menunjukkan ada pengaruh pendidikan kesehatan menggunakan media Booklet $(\Delta=6,80, p$ value $=0,012)$, media aplikasi SDIDTK $(\Delta=7,90, p$ value $=0,007)$ media Booklet + Aplikasi SDIDTK $(\Delta=10,80, p$ value $=0,005)$ terhadap kemandirian keluarga dalam pemantauan tumbuh kembang. Simpulan, Rata-rata skor kemandirian keluarga sangat baik pada kelompok intervensi pendidikan kesehatan dengan menggunakan media booklet+aplikasi SDIDTK karena menunjukkan peningkatan yang paling tinggi sehingga disarankan untuk menggunakan media booklet+aplikasi SDIDTK pendidikan kesehatan terkait dengan stimulasi, deteksi dan intervensi tumbuh kembang pada balita.
\end{abstract}

Kata Kunci : Aplikasi SDIDTK, Booklet, Kemandirian keluarga, Tumbuh kembang

\section{ABSTRACT}

This study aims to identify the effect of health education using booklet media and SDIDTK application media on family independence in monitoring the growth and development of children under five in the work area of West Bajo Health Center. This study uses Quasi Experimental with a pre and post-test approach without control. The results showed that there was an effect of health education using Booklet media $(\Delta=$ 6.80, $p$ value $=0.012)$, SDIDTK application media $(\Delta=7.90, p$ value $=0.007)$ Booklet media + SDIDTK Application $(\Delta=10.80, p$ value $=0.005)$ of family independence in monitoring growth and development. Conclusion, the average score of family independence is very good in the health education intervention group by using the booklet + SDIDTK application because it shows the highest increase so it is recommended to use the media booklet + SDIDTK application for health education related to stimulation, detection and growth and intervention in infants. .

Keywords: SDIDTK Application, Booklet, Family Independence, Growth and Development 


\section{PENDAHULUAN}

Anak merupakan dambaan setiap keluarga, setiap keluarga mengharapkan anaknya tumbuh kembang secara optimal (Soetjiningsih, 2015). Kualitas seorang anak dapat dinilai dari proses pertumbuhan dan perkembangan. Pertumbuhan adalah suatu proses pertambahan ukuran, baik volume, bobot, dan jumlah sel yang bersifat irreversible (tidak dapat kembali ke asal) sedangkan perkembangan adalah salah satu indikator dalam memantau kesehatan anak. Perkembangan anak mencakup perkembangan personal sosial, motorikakasar, bahasa, dan motorik halus (Kharisma \& Sri, 2016).

Mengingat masa sejak lahir sampai lima tahun pertama kehidupan anak merupakan masa yang relatif pendek dan tidak akan terulang kembali dalam kehidupan seorang anak, maka orangtua, pengasuh, pendidik atau masyarakat dan tenaga kesehatan harus dapat memanfaatkan kesempatan tersebut untuk membentuk anak menjadi anak yang berkualitas tinggi (Wijaya, 2009). Oleh karena itu orangtua perlu mengupayakan agar anaknya tumbuh dan berkembang optimal sesuai dengan potensi yang dimiliki antara lain melalui upaya Stimulasi, Deteksi dan Intervensi Dini Tumbuh Kembang (SDIDTK) pada balita (Rahayu \& Rahma, 2012).

Program Stimulasi, Deteksi dan Intervensi Dini Tumbuh Kembang (SDIDTK) merupakan kegiatan atau pemeriksaan untuk menemukan penyimpangan tumbuh kembang secara dini agar lebih mudah diintervensi serta memberikan konseling kepada keluarga bagaimana cara menstimulasi tumbuh kembang anak. Keterlambatan dalam mendeteksi penyimpangan akan berdampak terhadap sulitnya upaya intervensi dan berpengaruh pada tumbuh kembang anak berikutnya (Hermawan, 2011).

American Academy of Family Physicians (2012) memperkirakan 15\% dari anakanak di Amerika Serikat memiliki setidaknya satu keterlambatan perkembangan, namun kurang dari seperlima dari anak-anak menerima layanan intervensi dini sebelum usia tiga tahun. Perilaku pemberian stimulasi merupakan salah satu faktor yang dapat mempengaruhi perkembangan motorik anak. Anak yang mendapatkan stimulasi terarah dan teratur akan lebih cepat berkembang dibandingkan dengan anak yang kurang mendapat stimulasi, demikian juga untuk aspek perkembangan yang lain seperti bahasa dan sosial kemandirian (Larasati \& Maulidha, 2017).

Program Stimulasi, Deteksi dan Intervensi Dini Tumbuh Kembang (SDIDTK) merupakan revisi dari program Deteksi Dini Tumbuh Kembang (DDTK) yang telah dilakukan sejak tahun 1988 dan termasuk salah satu program pokok Puskesmas yang dilakukan di Posyandu. Cakupan pelayanan kesehatan anak balita pada tahun 2013 sebesar 57,34\%. Angka ini lebih kecil dibandingkan tahun 2012 sebesar 61,46\%, cakupan tahun 2013 belum mencapai target Standar Pelayanan Minimal (SPM) 90\%, begitu pula dengan target Provinsi Sulawesi Selatan belum mencapi 90\% dan cakupan pelayanan balita hanya mencapai 58\% (Dinas Provinsi Sul-Sel, 2014).

Rendahnya cakupan pelayanan kesehatan pada balita dipengaruhi oleh beberapa faktor, antara lain masih rendahnya partisipasi masyarakat untuk membawa anak balitanya ke fasilitas kesehatan dan posyandu secara rutin setiap bulan, sehingga tidak semua sasaran anak balita terpantau pertumbuhan dan perkembangannya. Ada anggapan di masyarakat bahwa kunjungan ke posyandu atau fasilitas kesehatan hanya dilakukan pada saat anak sakit serta belum semua masyarakat memahami bahwa penimbangan di posyandu bukan hanya sekedar untuk mengetahui berat badan anak tetapi lebih jauh untuk memantau status gizinya. Belum semua tenaga kesehatan terlatih menggunakan SDIDTK dan MTBS (Dinkes Luwu Utara, 2016). 
Menurut Soetjiningsih (2015) penyebab dari keterlambatan perkembangan anak salah satunya adalah kurang aktifnya perilaku orangtua dalam memberikan stimulasi, deteksi, dan intervensi dini tumbuh kembang kepada anak, ketidaktahuan orangtua terhadap pentingnya SDIDTK, namun sebagian orangtua belum memahami hal ini, pentingnya secara berkala melakukan SDIDTK anaknya sesuai dengan usia perkembangan. Perilaku tersebut timbul karena masih banyak orangtua yang beranggapan bahwa memberikan SDIDTK pada anak dengan sendirinya akan dimiliki jika waktunya tiba, padahal pengetahuan tentang SDIDTK harus dipahami dengan benar oleh setiap orangtua (Padila et al., 2019). Seorang ibu harus mengetahui tentang tahapan perkembangan anak dan stimulasi agar perkembangan anak menjadi optimal. Saat ibu mengetahui ada keterlambatan perkembangan anak dan penyebabnya karena ibu yang kurang aktif dalam pemberian SDIDTK, maka faktor utama yang harus dirubah adalah perilaku orangtua (Christi, 2013).

Selama ini upaya yang dilakukan untuk memaksimalkan pertumbuhan dan perkembangan anak yaitu dengan diadakannya pendidikan kesehatan kepada keluarga mengenai pentingnya pemantauan tumbuh kembang anak. Peningkatan kemandirian orangtua dalam stimulasi tumbuh kembang anak dilakukan dengan memberikan pendidikan kesehatan. Pendidikan kesehatan adalah sarangkaian upaya yang ditujukan untuk menggugah kesadaran, memberikan dan meningkatkan kemandirian sasaran pendidikan kesehatan serta peningkatan kesehatan individual, kelompok, keluarga dan masyarakat (Setiawan, 2008). Pendidikan kesehatan yang diberikan kepada orangtua diharapkan dapat menimbulkan interaksi antara orangtua sebagai caregiver yang memberikan stimulasi dan anak menunjukkan respon terhadap stimulasi yang diberikan serta didukung rangsangan dan objek yang digunakan untuk melakukan stimulasi seperti yang digambarkan oleh Barnard dalam teori parent child interaction (Alligood \& Tomey, 2010).

Pelaksanaan pendidikan kesehatan memerlukan media sebagai alat bantu, dengan adanya media materi pembelajaran yang rumit dan tidak jelas dapat disampaikan kepada sasaran dengan lebih sederhana dan mudah ditangkap (setiawan, 2008). Salah satu bentuk media yang digunakan dalam pelaksanaan pendidikan kesehatan adalah booklet. Booklet merupakan media penyampai pesan kesehatan dalam bentuk buku dengan kombinasi tulisan dan gambar. Kelebihan yang dimiliki media booklet yaitu informasi yang dituangkan lebih lengkap, lebih terperinci dan jelas serta bersifat edukatif. Selain itu, booklet yang digunakan sebagai media edukasi ini bisa dibawa pulang, sehingga dapat dibaca berulang dan disimpan (Nursalam \& Efendi, 2008).

Selain menggunakan booklet, media yang digunakan yaitu media elektronik berupa aplikasi. Aplikasi adalah alat bantu untuk mempermudah dan mempercepat proses pekerjaan dan bukan merupakan beban bagi penggunanya (Ibisa, 2010). Aplikasi dapat memfasilitasi dan mempermudah orangtua dalam memantau tumbuh kembang balitanya secara cepat dan akurat (Sudarmilah, 2011).

Hal ini sejalan dengan penelitian yang dilakukan oleh Saurina (2015) tentang aplikasi deteksi dini tumbuh kembang anak usia nol hingga enam tahun berbasis android. Hasil penelitian tersebut menyatakan bahwa aplikasi dapat dikategorikan sebagai alat bantu yang sangat baik dan bisa digunakan orangtua untuk mendeteksi dini tumbuh kembang anak secara mandiri. 


\section{METODE PENELITIAN}

Penelitian ini menggunakan desain quasi eksperimental dengan pendekatan pre and post-test without control. Populasi yang digunakan dalam penelitian ini adalah semua ibu yang memiliki anak usia balita di 5 posyandu yang berada di wilayah kerja Puskesmas Bajo Barat. Teknik pengambilan sampel menggunakan nonprobability sampling melalui incidental Sampling. Sampel dalam penelitian ini ialah ibu yang memiliki anak usia balita di wilayah kerja Puskesmas Bajo Barat yakni sebanyak 30 anak yang dibagi menjadi 3 kelompok. Proses pengambilan data dilakukan selama dua bulan. Instrumen yang digunakan ialah kuesioner kemandirian keluarga yang dibuat sendiri oleh peneliti.

Kriteria inklusi dalam penelitian ini yaitu keluarga yang memiliki anak usia balita di wilayah kerja Puskesmas Bajo Barat, keluarga yang memiliki dan bisa menggunakan Handphone android, dapat berkomunikasi secara wajar, bisa baca tulis, bersedia menjadi responden. Untuk kriteria eksklusi dalam penelitian ini yaitu keluarga dengan anak usia balita yang menderita kelainan kongenital atau penyakit kronis, terjadi penurunan status kesehatan secara drastis.

Penentuan kelompok pendidikan kesehatan menggunakan media booklet, aplikasi, dan booklet + aplikasi ditentukan oleh peneliti, responden dalam 1 wilayah posyandu yang sama dijadikan satu kelompok. Penelitian dilakukan di tiga Posyandu, setiap posyandu mendapatkan intervensi yang berbeda. Pengukuran tingkat kemandirian keluarga dilakukan sebelum intervensi menggunakan kuesioner, selanjutnya diberikan pendidikan kesehatan selama 60 menit selanjutnya dilakukan kunjungan kelas ibu balita pada minggu kedua setelah diberikan intervensi untuk review intervensi yang telah diberikan kemudian melakukan pengukuran post test 1 bulan setelah diberikan intervensi.

Sebelum dilakukan proses pengambilan data, orang tua calon responden diberikan informasi tentang penelitian yang akan dilakukan, keuntungan dan dampak yang mungkin dapat ditimbulkan selama proses penelitian, bila orang tua calon responden menyetujuinya maka dilanjutkan dengan pengisian lembar persetujuan menjadi responden.

\section{HASILPENELITIAN}

Tabel. 1

Distribusi Frekuensi Responden Berdasarkan Usia Ibu dan Pendidikan Ibu $(n=30)$

\begin{tabular}{lcccccc}
\hline \multicolumn{1}{c}{ Variabel } & & Frekuensi & \multicolumn{5}{c}{ Persentase (\%) } \\
& Booklet & Aplikasi & Kombinasi & Booklet & Aplikasi & Kombinasi \\
\hline Usia Ibu & & & & & & \\
a. $\leq 25$ tahun & 5 & 4 & 3 & 50 & 40 & 30 \\
b. $>25$ tahun & 5 & 6 & 7 & 50 & 60 & 70 \\
& 10 & 10 & 10 & 100,0 & 100,0 & 100,0 \\
\hline Pendidikan & & & & & & \\
Ibu & 6 & 5 & 5 & 60 & 50 & 50 \\
a. Rendah & 4 & 5 & 5 & 40 & 50 & 50 \\
b. Tinggi & 10 & 10 & 10 & 100,0 & 100,0 & 100,0 \\
\hline
\end{tabular}


Berdasarkan tabel 1 menjelaskan karakteristik responden berdasarkan usia ibu didapatkan dari 10 responden pada kelompok I yaitu responden berada di kelompok usia $\leq 25$ tahun dan $>25$ tahun dengan jumlah masing-masing sebanyak 5 orang (50\%). Pada kelompok II sebagian besar responden berusia $>25$ tahun sebanyak 6 orang $(60 \%)$ dan kelompok III sebagian besar responden berusia $>25$ tahun sebanyak 7 orang (70\%). Karakteristik responden berdasarkan pendidikan ibu didapatkan data bahwa pada kelompok I sebagian besar responden berpendidikan rendah sebanyak 6 orang (60\%), sedangkan pada kelompok II dan III jumlah responden yang berpendidikan tinggi dan rendah masing-masih berjumlah 5 orang (50\%).

Tabel. 2

Perbedaan Rata-Rata Kemandirian Keluarga Kelompok yang Diberikan Intervensi dengan Media Booklet, Media Aplikasi dan Media Booklet + Aplikasi

\begin{tabular}{clccc}
\hline Variabel & & Mean & Pvalue & $\mathrm{n}$ \\
\hline Media booklet & Sebelum & 16,00 & 0,012 & 10 \\
& Sesudah & 22,80 & & \\
& Selisih & 6,80 & & 10 \\
\hline Media aplikasi SDIDTK & Sebelum & 14,70 & 0,007 & \\
& Sesudah & 22,60 & & 10 \\
& Selisih & 7,90 & & \\
\hline Media booklet+aplikasi & Sebelum & 13,20 & 0,005 & \\
SDIDTK & Sesudah & 24,00 & & \\
& Selisih & 10,80 & & \\
&
\end{tabular}

Sumber: Data Primer, 2019

Berdasarkan tabel 2 menunjukkan bahwa pada kelompok ibu yang diberikan intervensi pendidikan kesehatan dengan menggunakan media booklet terjadi peningkatan kemandirian sebelum dan setelah diberikan intervensi. Nilai selisih antara sebelum dan setelah intervensi adalah 6,80. Hasil uji statistik didapatkan nilai $\mathrm{p}$ value $=$ $0,012(<0.05)$, sehingga dapat disimpulkan bahwa ada perbedaan antara tingkat kemandirian keluarga dalam pemantauan tumbuh kembang balita sebelum dan sesudah diberikan inervensi pendidikan kesehatan menggunakan media booklet.

Berdasarkan tabel 2 juga menunjukkan bahwa pada kelompok ibu yang diberikan intervensi pendidikan kesehatan dengan menggunakan media aplikasi SDIDTK terjadi peningkatan kemandirian sebelum dan setelah diberikan intervensi. Nilai selisih antara sebelum dan setelah intervensi adalah 7,90. Hasil uji statistik didapatkan nilai $\mathrm{p}$ value $=$ $0,007(<0,05)$, sehingga dapat disimpulkan bahwa ada perbedaan antara tingkat kemandirian keluarga dalam pemantauan tumbuh kembang balita seblum dan sesudah diberikan inervensi pendidikan kesehatan menggunakan media aplikasi SDIDTK.

Tabel diatas juga menunjukkan bahwa pada kelompok ibu yang diberikan intervensi pendidikan kesehatan dengan menggunakan media booklet+aplikasi SDIDTK terjadi peningkatan kemandirian sebelum dan setelah diberikan intervensi. Nilai selisih antara sebelum dan setelah intervensi adalah 10,80. Hasil uji statistik didapatkan nilai $\mathrm{p}$ value $=0,005(<0,05)$, sehingga dapat disimpulkan bahwa ada perbedaan antara tingkat kemandirian keluarga dalam pemantauan tumbuh kembang balita seblum dan sesudah diberikan inervensi pendidikan kesehatan menggunakan media booklet+aplikasi SDIDTK.

Tabel diatas juga menyatakan bahwa selisih mean tingkat kemandirian sebelum dan sesudah diberikan intervensi pendidikan kesehatan menggunakan media booklet ialah 6,80, media aplikasi SDIDTK ialah 7,90 dan media booklet+aplikasi SDIDTK 
ialah 10,80. Berdasarkan ketiga intervensi di atas dapat disimpulkan bahwa intervensi kombinasi antara booklet dan aplikasi SDIDTK memiliki selisih paling besar dari pada dua intervensi lainnya, sehingga intervensi kombinasi antara booklet dan aplikasi SDIDTK lebih direkomendasikan untuk digunakan dalam meningkatkan kemandirian keluarga dalam pemantauan tumbuh kembang balita.

\section{PEMBAHASAN}

Responden dalam penelitian ini sebanyak 30 ibu yang memilik anak usia balita. Usia responden terbanyak dalam penelitian ini $>25$ tahun, menurut Depkes RI tahun 2009 usia >25 tahun masuk kategori dewasa. Menurut Hurlock (2012) usia dewasa awal merupakan masa dimana peran sebagai pasangan hidup dan ibu yang selalu mempersembahkan waktu untuk merawat dan mendidik anak. Selain hal tersebut peran ibu pada usia ini menstimulasi tumbuh kembang anak dan menfokuskan dalam pola pengasuh terhadap anak. Ibu yang memiliki usia lebih dewasa merasa lebih mandiri dalam melakukan pemantauan tumbuh kembang balita dikarenakan ibu merasa sudah memiliki pengalaman dalam melakukan stimulasi, deteksi dan intervensi dini.

Sebagian besar responden dalam penelitian ini berpendidikan rendah. Pendidikan ibu akan berkontribusi dalam meningkatkan kemampuan ibu dalam pemantauan tumbuh kembang balita. Seseorang dengan pendidikan tinggi akan mampu mengelola, mengatasi dan menggunakan koping efektif dan konstruktif daripada seseorang yang memiliki pendidikan rendah.

Menurut Wijaya (2009) variabel pendidikan merupakan konfounding terhadap pengaruh umur, artinya ibu yang berumur muda bisa saja memiliki perilaku yang baik dalam proses tumbuh kembang anaknya jika ibu tersebut memiliki pendidikan yang baik begitupun sebaliknya ibu yang berumur tua bisa saja memiliki perilaku yang kurang jika pendidikan ibu tersebut rendah.

Ibu dengan pendidikan rendah akan berpengaruh pada sikap dan perilaku yang kurang dalam menstimulasi perkembangan anak. Anak dengan ibu yang memiliki tingkat pendidikan dan wawasan yang tinggi akan memperhatikan dan merawat anak sesuai dengan usia perkembangannya, melakukan penyesuaian pribadi dan sosial yang lebih baik serta dapat meningkatkan kualitas pengasuhan dan membantu anak mencapai tahapan perkembangannya (Yulita, 2014).

Hasil penelitian menunjukkan bahwa ada perbedaan tingkat kemandirian keluarga sebelum dan sesudah diberikan intervensi pendidikan kesehatan menggunakan media booklet ( $\mathrm{p}$ value $=0,012$ ) dengan $\Delta=6,80$. Penggunaan booklet akan memudahkan keluarga dalam belajar karena didesain berbentuk buku dan banyak memuat informasi dibandingkan dengan yang lain (Aini, 2010). Pada diri seseorang, kemandirian akan terbentuk setelah terjadi proses tahu terlebih dahulu. Informasi dari media akan membawa pesan sugestif yang jika cukup kuat akan memberi dasar efektif dalam menilai sesuatu sehingga terbentuk arahan sikap tertentu. Perubahan sikap terjadi ketika stimulus diterima kemudian diubah menjadi bentuk respon yaitu kesediaan untuk bertindak, sehingga dengan munculnya sikap ibu menunjukkan adanya penerimaan ibu terhadap booklet yang diberikan sebagai stimulus. Media booklet yang diberikan metode ceramah cenderung lebih baik digunakan untuk meningkatkan pengetahuan sementara untuk peningkatan sikap metode diskusi kelompok, demonstrasi, bermain peran (role play) atau metode permainan cenderung lebih baik (Notoadmojo, 2012). 
Hasil penelitian yang dilakukan oleh Utami (2018) dengan menggunakan buku pedoman (Booklet) menunjukkan hasil bahwa terdapat perbedaan yang bermakna antara pengetahuan sebelum dan sesudah mendapatkan pelatihan metode kombinasi ceramah, tanya jawab dan demonstrasi $(\mathrm{p}=0,010)$, dimana persentase ibu yang mendapatkan pelatihan metode kombinasi ceramah, tanya jawab dan demonstrasi mempunyai pengetahuan yang kurang $(49,57 \%)$ saat sebelum intervensi dan setelah intervensi mempunyai pengetahuan baik $(82,61 \%)$. Berdasarkan hal tersebut diketahui bahwa pendidikan kesehatan dengan menggunakan media booklet dapat meningkatkan kemandirian keluarga dalam pemantauan tumbuh kembang.

Hasil penelitian menunjukkan bahwa ada perbedaan tingkat kemandirian keluarga sebelum dan sesudah diberikan intervensi pendidikan kesehatan menggunakan media aplikasi SDIDTK ( $p$ value $=0,007$ ) dengan $\Delta=7,90$. Menurut Ibisa (2010) perkembangan ilmu pengetahuan dan teknologi mengarah pada perubahan yang signifikan dan menuju era praktis. Penggunaan media Aplikasi bertujuan untuk mempermudah dan mempercepat proses pekerjaan dan bukan merupakan beban bagi penggunanya. Aplikasi tumbuh kembang merupakan media untuk memudahkan ibu untuk mengontrol pertumbuhan dan perkembangan buah hati mereka dimanapun dan kapanpun meraka berada (Sudarmilah, 2011). Aplikasi ini dapat mendeteksi gangguan tumbuh kembang anak berdasarkan informasi dan masukan dari pengguna menggunakan instrumen kuesioner pra skrining perkembangan, dengan menghitung jumlah jawaban dari pengguna aplikasi mengenai tumbuh kembang anak (Saurina, 2015).

Hasil penelitian yang dilakukan oleh Suryani \& Carudin (2016) menyatakan bahwa aplikasi SDIDTK berbasis android dapat meningkatkan motivasi bidan dalam melakukan SDIDTK. Berdasarkan hal tersebut dapat disimpulkan bahwa dengan adanya aplikasi SDIDTK dapat meningktakan kemandirian keluarga dalam melakukan pemantauan tumbuh kembang balita, sehingga tumbuh kembang yang mengalami gangguan secara dini akan terdeteksi dan balita akan mendapatkan stimulasi, intervensi sesuai dengan kebutuhannya guna mewujudkan anak Indonesia yang berkualitas.

Hasil penelitian menunjukkan bahwa ada perbedaan tingkat kemandirian keluarga sebelum dan sesudah diberikan intervensi pendidikan kesehatan menggunakan media booklet+aplikasi SDIDTK ( $\mathrm{p}$ value $=0,005$ ) dengan $\Delta=10,80$. Menurut Walianti (2014) proses pengembangan karakter kemandirian dilakukan secara berulang-ulang yang akan menjadi suatu kebiasaan seperti kegiatan rutin, kegiatan secara spontan, kegiatan yang dilakukan dengan inisiatif sendiri, tanggung jawab serta disiplin. Suatu kegiatan jika dilakukan secara berulang-ulang akan membentuk perilaku pada diri seseorang yang meliputi sikap, perilaku dan keterampilannya. Pada tahap permulaan akan terlihat sedikit perubahan suatu tingkah laku. Hal ini akan terus berubah sesuai dengan kegiatan yang dilakukan secara terus menerus sehingga muncul kinerja yang baik atau kebiasaan yang baik (Hikmat, 2014).

Kegiatan pemberian pendidikan kesehatan dengan menggunakan Booklet+aplikasi memberikan pengaruh yang lebih signifikan dibandingkan dengan memberikan pendidikan kesehatan hanya menggunakan booklet atau aplikasi saja, karena dengan memberikan pendidikan kesehatan menggunakan booklet+aplikasi sama halnya dengan memberikan pembelajaran secara berdiskusi dan langsung mengaplikasikan ilmu yang diberikan. 
Hal ini sesuai dengan teori yang dikemukakan oleh seorang pakar yang bernama Edgar Dale (1969) dalam Arsyad (2013) yang kemudian memberikan bobot secara persen dalam penelitian-penelitian tentang efektifitas belajar. Model pembelajaran terbagi menjadi 2 yaitu aktif dan pasif. Pada model pembelajaran pasif, rata-rata itulah model yang masih digunakan secara umum dalam model belajar saat ini. Membaca memberikan andil penguasaan materi $10 \%$, mendengarkan $20 \%$, dan melihatnya secara langsung memberikan konstribusi sebesar 30\%. Sedangkan model pembelajaran aktif, dimana ketika kita mengatakan atau mengajarkan orang atau berdiskusi, maka itu bisa memberikan $70 \%$ pemahaman terhadap materi yang dikuasai, serta jika kita aktif melakukan/mengaplikasikan ilmu, maka hal tersebut berkonstribusi $90 \%$ terhadap pemahaman kita terhadap materi pelajaran yang berdampak terhadap sikap dan kemandirian seseorang.

Hasil penelitian yang dilakukan oleh Wicaksari (2012) tentang hubungan antara penggunaan media pembelajan dengan kemandirian, menunjukkan bahwa semakin tinggi penggunaan media pembelajaran, semakin tinggi kemandirian, dan semakin rendah penggunaan media pembelajaran, semakin rendah kemandirian ( $p$ value $0,002<$ $0,05)$.

\section{SIMPULAN}

Berdasarkan hasil penelitian dapat disimpulkan bahwa terdapat perbedaan nilai rata-rata tingkat kemandirian sebelum dan sesudah diberikan intervensi pendidikan kesehatan yaitu menggunakan media Booklet, media aplikasi SDIDTK, media Booklet + Aplikasi SDIDTK terhadap kemandirian keluarga dalam pemantauan tumbuh kembang.

\section{SARAN}

Peneliti menyarankan kepada tenaga kesehatan untuk senantiasa memberikan pendidikan kesehatan kepada keluarga mengenai cara pemantauan tumbuh kembang balita dengan melakukan stimulasi, deteksi, dan intervensi dini menggunakan kombinasi media booklet dan aplikasi SDIDTK.

Bagi peneliti selanjutnya disarankan agar lebih memperhatikan waktu. Waktu penelitian diharapkan tidak dilakukan pada waktu responden sibuk, sehingga tingkat pengembalian kuesioner dapat lebih tinggi, dan mendapatkan hasil yang lebih akurat. Peneliti selanjutnya diharapkan dapat melakukan penelitian ditempat yang lebih luas dan dengan jumlah sampel yang lebih banyak sehingga data yang diperoleh dapat digeneralisasikan lebih baik. Dengan demikian hasil penelitian yang dilakukan oleh peneliti selanjutnya dapat menggambarkan kemandirian yang lebih akurat.

\section{DAFTRA PUSTAKA}

Aini, F. (2010). Pengaruh Pendidikan Kesehatan Reproduksi Remaja Melalui Media Booklet terhadap Perubahan Pengetahuan dan Sikap Santri tentang Kesehatan Reproduksi di Pesantren Darul Hikmah dan Ta'dib Al Syakirim di Kota Medan Tahun 2010. Universitas Sumatera Utara (USU)

Alligood, M., \& Tomey, T. (2010). Nursing Theorists and Their Work. Seven. United States of America: Elsevier

American Academy of Family Physicians. (2012). Clinical Preventive Service Recommendation: Speech and Language Delay. Washington D. C:APA Arsyad, A. (2013). Media Pembelajaran. Jakarta: PT. Raja Grafindo Persada 
Christi, A. Y. (2013). Hubungan Pengetahuan Ibu tentang Stimulasi Dini dengan Perkembangan Motorik pada Anak Usia 6-24 Bulan di Kecamatan Mayang Kabupaten Jember. Universitas Jember

Dinas Kesehatan Kabupaten Luwu Utara. (2016). Laporan Kinerja Tahunan. Masamba: Dinkes Luwu Utara

Dinas Provinsi Sulawesi Selatan. (2014). Profil Kesehatan Sulawesi Selatan 2013. Makassar. Dinkes Makassar

Hermawan, L. (2011). Pelayanan Kesehatan dan Dasar. Jakarta: Kemenkes

Hikmat, A. (2014). Kreativitas, Kemampuan Membaca, dan Kemampuan Apresiasi Cerpen. Jakarta: Uhamka Press

Hurlock, E. B. (2012). Psikologi Perkembangan, Suatu Pendekatan Sepanjang Rentang Kehidupan (Terjemahan). Jakarta: Erlangga

Ibisa, I. (2010). Sistem Evaluasi dan Auditing Sistem Aplikasi bagi Perusahaan. Yogyakarta

Kharisma, K., \& Sri, W. (2016). Faktor Pendapatan dan Pendidikan Keluarga terhadap Perkembangan Motorik Halus Anak Usia 3-4 Tahun. Jurnal penelitian kesehatan Suara Forikes, 7(1). ISSN: 2086-3098

Larasati, D., \& Maulidha, M. (2017). Faktor-Faktor yang Mempengaruhi Keterlambatan Perkembangan Anak Usia 1-3 Tahun di Desa Cangkringsari Kecamatan Sukodono Kabupeten Sidoarjo. Journal of Issues in Midwifery, 1(1). E-ISSN: 2549-6581

Notoatmodjo, S. (2012). Konsep Perilaku dan Perilaku Kesehatan. Promosi Kesehatan dan Perilaku Kesehatan. Jakarta: Rineka Cipta; p. 131-46

Nursalam, N., \& Efendi, F. (2008). Pendidikan dalam Keperawatan. Jakarta: Salemba Medika

Padila, P., Andari, F, N., Andri, J. (2019). Hasil Skrining Perkembangan Anak Usia Toddler antara DDST dengan SDIDTK. Jurnal Keperawatan Silampari, 3(1), 244-256. https://doi.org/https://doi.org/10.31539/jks.v3i1.809

Rahayu, S., \& Rahma, C. A. (2012). Karakteristik Ibu Balita Kaitannya dengan Pelaksanaan Stimulasi, Deteksi dan Intervensi Dini Tumbuh Kembang Anak Balita. Media GII Indonesia, 11(1), 155-60

Saurina, N. (2015). Aplikasi Deteksi Dini Tumbuh Kembang Anak Usia Nol Hingga Enam Tahun Berbasis Android. Jurnal Buana Informatika, 7(1), 65-74

Setiawan, S. (2008). Pendidikan Kesehatan. Jakarta: Trans Info Media

Soetjiningsih, S. (2015). Tumbuh Kembang Anak. Jakarta: EGC

Sudarmilah, E. (2011). Sistem Monitoring Pertumbuhan Balita Berbasis Web (KMS Online). Simposium nasional RAPI X FT UMS ISSN: 1412-9612 E-32

Suryani, L., \& Carudin, C. (2016). Efektifitas Aplikasi SDIDTK Berbasis Android dalam Peningkatan Motivasi Bidan Melakukan SDIDTK pada Balita di Kecamatan Cilamaya Kulon Kabupaten Karawang. Universitas Singaperbangsa Karawang

Utami, F, W. (2018). Pengembangan Media Booklet Teknik Kaitan untuk Siswa Kelas X SMKN 1 Saptosari Gunung Kidul. Universitas Negeri Yogyakarta

Walianti, W. (2014). Pengembangan Karakter Kemandirian Melalui Program Boarding School. Universitas Surakarta

Wicaksari, E. (2012). Hubungan antara Penggunaan Media Pembelajaran dengan Kemandirian Belajar Mahasiswa FKIP-PE UKSW Salatiga Angkatan Tahun 2008-2009 Semester II Tahun Ajaran 2011-2012. Salatiga 
Wijaya, A. M. (2009). Pentingnya Stimulasi, Deteksi, dan Intervensi Dini Tumbuh Kembang (SDIDTK atau "SIDIDITK") anak. Jakarta: Depdiknas

Yulita, R. (2014). Hubungan Pola Asuh Orangtua terhadap Perkembangan Anak Balita di Posyandu Sakura Ciputat Timur. Universitas Negeri Syarif Hidayatullah Jakarta 